\title{
Study on the Service Performance and Service Quality of Online Banking
}

\author{
Chao-Feng Hsu ${ }^{1,2}$, Bi-Ru Lee ${ }^{3}$ \\ ${ }^{1}$ Zhou Enlai School of Government, Nankai University, Tianjin 300071, China \\ ${ }^{2}$ Zhongshan Institute, University of Electronic Science and Technology of China, Guangdong \\ 528402, China \\ ${ }^{3}$ Law School, Nankai University, Tianjin 300071, China \\ visonhsu8989@126.com,maggen_lee@hotmail.com
}

\begin{abstract}
Online banking not only saves many labor costs of banks, but also time of users. The key factors influencing the service quality of online banking are being explored till now, because the demands of customers are ever-changing. It is a prominent challenge for the practitioners of the banking and financial sectors to distinguish themselves in the Internet financial market, enhance service quality, and strengthen competitive strategies. Importance-Performance Analysis Model is a method commonly adopted to assess performance and analyze competitive strategies. This study employed IPA to probe into the service performance, advantages, disadvantages of the online banking of the sample and the analysis results will serve as the basis of the company for improvement.
\end{abstract}

Keywords: online banking, service quality, competitive strategies, Importance-Performance Analysis Model, service performance

\section{Introduction}

Online banking not only saves many labor costs of banks, but also time of users ${ }^{1}$. Aladwani ${ }^{2}$ argued that online banking contains a variety of services. Customers can receive relevant services, such as asset report, cross-account transfer, and bill payment, via the Internet without leaving their homes or organizations. Sayar \& Wolfe ${ }^{3}$ defined online banking as referred to the transactions with banks through high-tech products like digital TV and mobile, and the Internet. This study deemed that online banking stood for the banking or financial services and transactions, such as deposit, remittance, transfer, payment, securities trading, insurance service, and query of interest rate received by customers through the Internet and electronic devices anytime and anywhere without no need to go to the counter. Therefore, online banking can be considered as a virtual outlet set up on the Internet by banks for the convenience of the public. Online banking boasts the following functions and characteristics ${ }^{4-5}$ :

It is a financial institution. A physical outlet may or may not be needed. (2) It can reduce the cost to establish and operate branches. (3) It fully masters the information of customers and expands customer groups. (4) It can be used anytime anywhere via the Internet. (5) It provides real-time and sufficient financial information. (6) It offers high autonomy and privacy to customers. (7) It enhances service efficiency and saves the time of customers waiting in queue. (8) It can reduce the errors during manual operation. (9) It weakens the long-term and close relationship between traditional banks and customers.

Importance-Performance Analysis Model is a method commonly adopted to assess performance and analyze competitive strategies. This study employed IPA to probe into the service performance, advantages, disadvantages of the online banking of the sample and the analysis results will serve as the basis of the company for improvement.

\section{Literature Review}

\subsection{Characteristics of online banking}

With the progress of science and technology, the Internet has become more and more mature and gradually integrated into our daily life. Various economic activities continue to increase, promoting 
emerging network industries, such as network marketing, online shopping, and online community. "Coverage of the population with the access to the Internet", "market share of network ads", and "market share of online shopping" have become important indicators of the global network economy. Increasing people use online banking because ${ }^{4,6}$ :

\subsubsection{It is not limited by geography and time. And its service efficiency is high.}

Online banking is not limited by geography and time, which allows customers to conduct product transactions or receive services via the Internet not restricted to the business hours of traditional banks. Online banking is operated automatically. It not only feedbacks information after transactions instantly to customers, but also has extremely low error rate in tens of thousands of transactions handled. For bankers, it can raise bank reputation and retain customers. And for customers, the risk or inconvenience caused by manual operation can be reduced.

\subsubsection{Wide services}

Nowadays, online banking has strong functions. It not only covers the services of traditional banks like deposit and remittance, but also provides various financial services like securities, insurance, and information query, so as to meet the demands of customers, raise customer satisfaction, become "network financial supermarket", and offer one-stop service.

\subsubsection{Low cost}

Online banking is set up on the convenient and cheap Internet rather than expensive physical outlets. The automatic operation of online banking can save labor and operational cost of traditional banks, and reduce error rate and bank loss. With respect to the operational cost of banks, according to the survey by Allen Milton International Management Consulting Company, the operational cost of online banking only accounted for $15 \%$ to $20 \%$ of the operating revenue. In contrast, the operational cost of traditional banks accounted for approximately $60 \%$ of their operating revenue. Therefore, the setup of online banking can substantially reduce the operational cost.

\subsubsection{Interaction}

Another advantage of online banking is interaction. This interaction is different from the traditional interpersonal interaction. It means that all the transactions done via online banking can be displayed real-time. Based on the content of the previous transaction, customers can adjust their decision on the next one so as to seize crucial time point to gain profit, which is impossible for traditional banks.

\subsubsection{Customized services}

The functions of online banking have been gradually improved. The services of online banking of various banks are similar. In such a competitive environment, it is the key to success if a bank can provide customized services based on customer demands. Bankers can analyze according to the transaction records of online banking, determine the value and level of customers, understand the demands of customers at each level, and then provide services correspondingly. Since resources are limited, through data analysis, resources can be allocated to the customers with the most value so that bankers can retain them customers and create lifelong value of customers.

\subsection{Definition and measurement of the service quality of online banking}

Zeithaml et al. ${ }^{7}$ identified the following seven major dimensions of the service quality of online banking:

(1) Efficiency: It is measured by the convenience and speed of query, easiness of use, and transaction speed of a website.

(2) Reliability: It is measured based on the stability of function and smoothness of transaction of a website.

(3) Fulfillment: It is measured if a website can truly subscribe, deliver, and provide services.

(4) Privacy: It is measured by the protection of transaction data and personal information security.

(5) Responsiveness: It is measured by the response speed, flexibility of solution, and processing quality to solve problems by a website.

(6) Compensation: It refers to the intention of a website to compensate a customer in case of problem.

(7) Contact: It is measured by the accessibility of customers to obtain customer service and support 
of a website through various contact channels.

This study referred to the dimensions of Zeithaml et al. ${ }^{7}$ and proposed 10 indicators to assess the service quality and performance of online banking. The 10 indicators are: website guidance, functional operation, transaction query, privacy, security and correctness, bank reputation and comment, compensation for problematic transactions, service attitude, service efficiency, and professionalism.

\section{Research Method}

The framework related to Importance-Performance Analysis Model was first proposed by Martilla $\&$ James ${ }^{8}$ who then applied it to actual use. In IPA, the averages of the importance and performance of service attributes were marked on a $2 \mathrm{D}$ figure ${ }^{9-13}$. The vertical axis refers to importance, while the horizontal one, performance, as shown in Figure $1^{14-18}$.

4 quadrants in IPA. Each had a definition ${ }^{19-24}$ : (1)Concentrate here: Customers believe that the importance of products or service attributes is high but the performance of the company is low. (2)

Keep up the good work: Customers believe that the importance of products or service attributes, as well as the performance of the company are high. (3)Low priority: Customers believe that the importance of products or service attributes, as well as the performance of the company are low. (4)Possible overkill: Customers believe that the importance of products or service attributes is low, but the performance of the company is high.

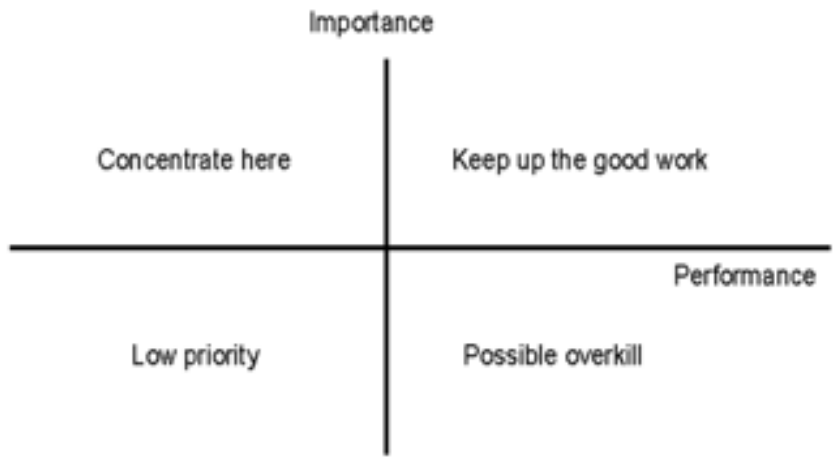

Fig.1 Analysis of importance and performance

Through the classification of different regions, managers can make the most out of limited resources and provide the priority of improvement so as to enhance performance ${ }^{25-28}$.

\section{Research Results and Discussion}

Company $\mathrm{X}$ is one of the top ten commercial banks in mainland China. This study considered $\mathrm{X}$ as its subject and probed into its service quality and competitive strategies. The questionnaire of this study adopted Likert 7-point scale covering a total of 10 indicators. The respondents include 10 professors, 27 senior managers in the banking industry, and 3 governmental officials. A total of 40 copies of questionnaire had been distributed, while 33 valid ones were collected. The recovery rate is $82.50 \%$.

This study used the averages of importance (5.85) and performance (5.79) as standard coordinate to determine the performance of each indicator. See Table 1 for details.

Table 1 The measurement of service quality and competitive strategies of online banking

\begin{tabular}{|l|l|c|c|l|}
\hline No. & Indicator & Importance & Performance & Competitive strategies \\
\hline 1. & Website guidance & 5.6 & 5.5 & Low priority \\
\hline 2. & Functional operation & 5.6 & 5.6 & Low priority \\
\hline 3. & Transaction query & 5.2 & 5.9 & Possible overkill \\
\hline 4. & Privacy & 6 & 6.2 & Keep up the good work \\
\hline 5. & Security and correctness & 6.2 & 6 & Keep up the good work \\
\hline 6. & Bank reputation and comment & 6.1 & 5.9 & Keep up the good work \\
\hline 7 & Compensation for problematic transactions & 5.9 & 6.2 & Keep up the good work \\
\hline 8 & Service attitude & 5.9 & 5.6 & Concentrate here \\
\hline
\end{tabular}




\begin{tabular}{|l|l|c|c|l|}
\hline \multicolumn{5}{|l|}{ Table 1, cont. } \\
\hline 9 & Service efficiency & 6.0 & 5.5 & Concentrate here \\
\hline 10 & Professionalism & 6.0 & 5.5 & Concentrate here \\
\hline Average & & 5.85 & 5.79 & \\
\hline
\end{tabular}

According to the results of IPA analysis, the service quality and competitive strategies of bank $\mathrm{A}$ is analyzed as follows:

High importance, high performance: (4) "privacy", (5) "security and correctness", (6) "bank reputation and comment", and (7) "compensation for problematic transactions" belong to "Keep up the good work". These are the advantages of the service quality of online banking of bank A, which shall be kept up to maintain god service performance.

High importance, low performance: (8) "service attitude", (9) "service efficiency", and (10) "professionalism" belong to "Concentrate here". Bank A must invest more resources to raise the service quality and competitiveness of the three indicators, and strengthen service attitude, service efficiency, and professionalism, so as to turn disadvantages into advantages and raise its competitive performance.

Low importance, low performance: (1) "website guidance" and (2) "functional operation" belong to "Low priority". The two indicators of service quality can have the lowest priority. When bank A has surplus resources, they can be improved.

Low importance, high performance: (3) "transaction query" belongs to Possible overkill". The good performance of bank $\mathrm{A}$ fails to bring about more service performances to the company. The resources of the company shall be shifted to other competitive indicators.

\section{Conclusion}

The functions of online banking have been gradually improved. The services of online banking of various banks are similar. In such a competitive environment, it is the key to success if a bank can provide customized services based on customer demands. This study proposed 10 indicators to assess the service quality and performance of online banking.

The four indicators of bank A, that is, (4) "privacy", (5) "security and correctness", (6) "bank reputation and comment", and (7) "compensation for problematic transactions" belong to "Keep up the good work". These are the advantages of the service quality of online banking of bank A, which shall be kept up to maintain god service performance. The indicators of (8) "service attitude", (9) "service efficiency", and (10) "professionalism" belong to "Concentrate here" with low performance. Bank A must invest more resources to raise the service quality and competitiveness of the three indicators, and strengthen service attitude, service efficiency, and professionalism, so as to turn disadvantages into advantages and raise its competitive performance.

\section{References}

[1] Rust, R.T. and Kannan, P.K.. E-Service: A New Paradigm for Business in the Electronic Environment. Communications of the ACM, 46(6), (2003), p. 37-42

[2] Aladwani, A.M. Online Banking: A Field Study of Drivers, Development Challenges, and Expectations. International Journal of Information Management, 21(3), (2001), p. 213-225

[3] Sayar, C. and Wolfe, S. Internet Banking Market Performance: Turkey Versus the UK. International Journal of Bank Marketing, 25(3), (2007), p. 122-141

[4] Tsai, S.B., Li, G., Wu, C.H., Zheng, Y., et al. An empirical research on evaluating banks' credit assessment of corporate customers. SpringerPlus, (2016), 5:2088. DOI 10.1186/s40064-016-3774-0.

[5] Zhang, X., Deng Y., Chan, F. T., Xu, P., et al.. IFSJSP: A novel methodology for the Job-Shop Scheduling Problem based on intuitionistic fuzzy sets. International Journal of Production Research, 51(17), (2013), p. 5100-5119

[6] Tsai, S.B., Chen, K.Y., Zhao, H., Wei, Y.M., et al. Using a Mixed Model to Explore Evaluation Criteria for Bank Supervision: A Banking Supervision Law 
Perspective.PLoSONE,11(12),(2016):e0167710.

[7] Zeithaml, V.A., Parasuraman, A. \& Malhotra, A. Service Quality Delivery through Web Sites: A Critical Review of Extant Knowledge. Academy of Marketing Science, 30(4), (2002), p. 362-375

[8] Martilla, J. A. \& James, J. C. Importance-Performance Analysis. Journal of Marketing, 41 (1), (1977), p. 77-79

[9] Tsai, S.B., Wei, Y.M., Chen, K.Y., Xu, T., et al. Evaluating Green Suppliers from Green Environmental Perspective. Environment and Planning B-Planning \& Design, 43(5), (2016), p. 941-959

[10] Tsai,S.B. Using Grey Models for Forecasting China's Growth Trends in Renewable Energy Consumption. Clean Technologies and Environmental Policy, 18, (2016), p. 563-571

[11] Guo, J.J. and Tsai, S.B. Discussing and Evaluating Green Supply Chain Suppliers: A Case Study of the Printed Circuit Board Industry in China. South African Journal of Industrial Engineering, 26(2), (2015), p. 56-67

[12] Tsai, S.B., Huang, C.Y., Wang, C.K., Chen, Q., et al. Using a Mixed Model to Evaluate Job Satisfaction in High-Tech Industries. Plos One, 11(5), (2016), e0154071. doi:10.1371/journal.pone.0154071

[13] Lee, Y.C., Chu, W.H., Chen, Q., Tsai, S.B., et al. Integrating DEMATEL Model and Failure Mode and Effects Analysis to Determine the Priority in Solving Production Problems. Advances in Mechanical Engineering, 8(4), (2016), p. 1-12

[14] Tsai, S.B., Xue, Y., Zhang, J., Chen, Q., et al. Models for Forecasting Growth Trends in Renewable Energy. Renewable \& Sustainable Energy Reviews, (2016), DOI: 10.1016/j.rser.2016.06.001

[15] Qu, Q., Chen, K.Y., Wei, Y.M., et al. Using Hybrid Model to Evaluate Performance of Innovation and Technology Professionals in Marine Logistics Industry Mathematical Problems in Engineering, (2015), Article ID 361275, 8 pages, http://dx.doi.org/10.1155/2015/361275

[16] Zhou, J. Wang, Q., Tsai, S.B., et al. How to Evaluate the Job Satisfaction of Development Personnel. IEEE Transactions on Systems Man Cybernetics-Systems, (2016), 10.1109/TSMC.2016.2519860.

[17] Su, J. M., Lee, S. C., Tsai, S. B. and Lu, T. L. A comprehensive survey of the relationship between self efficacy and performance for the governmental auditors. SpringerPlus, (2016), 5:508. DOI 10.1186/s40064-016-2104-X.

[18] Tsai, S.B., Lee, Y.C. \& Guo, J.J. Using modified grey forecasting models to forecast the growth trends of green materials. Proceedings of the Institution of Mechanical Engineers, Part B: Journal of Engineering Manufacture, 228(6): (2014), p. 931-940

[19] Chen, H.M., Wu, C.H., Tsai, S.B., Yu, J., et al. Exploring key factors in online shopping with a hybrid model. SpringerPlus, (2016), 5:2046. DOI 10.1186/s40064-016-3746-4.

[20] Deng, X.Y., Hu, Y., Deng Y. and Mahadevan, S.Environmental impact assessment impact assessment based on numbers. Expert Systems with Applications, 41 (2), (2014), p. 635-643

[21] Wang, J., Yang, J., Chen Q. and Tsai, S.B. Collaborative Production Structure of Knowledge-sharing Behavior in Internet Communities. Mobile Information Systems, Article ID 8269474, 9 pages, http://dx.doi.org/10.1155/2016/8269474. (2016)

[22] Wang, J., Yang, J., Chen Q. and Tsai, S.B. Creating the Sustainable Conditions for Knowledge Information Sharing in Virtual Community. SpringerPlus, (2016), 5:1019, DOI 10.1186/s40064-016-2702-7

[23] Lee, Y.C., Wang, Y.C., Chien, C.H., Wu, C.H., et al. Applying Revised Gap Analysis Model in Measuring Hotel Service Quality, SpringerPlus, (2016), 5:1191, DOI 10.1186/s40064-016-2823-z.

[24] Lee, Y.C., Wang, Y.C., Lu, S.C., Hsieh, Y.F., et al. An Empirical Research on Customer Satisfaction Study: A Consideration of Different Levels of Performance. SpringerPlus, (2016), 5:1577, DOI 10.1186/s40064-016-3208-z.

[25] Chin, T., Tsai, S.B., Fang, K., Zhu, W., et al. EO-Performance relationships in Reverse 
Internationalization by Chinese Global Startup OEMs: Social Networks and Strategic Flexibility. PLoS ONE, 11(9): (2016), e0162175, doi:10.1371/journal.pone.0162175

[26] Lee, S.C., Su, J.M., Tsai, S.B., Lu, T.L., et al. A comprehensive survey of government auditors' self efficacy and professional Development for improving audit quality. SpringerPlus, (2016), 5:1263, DOI 10.1186/s40064-016-2903-0

[27] Chen, H.M., Wu, C.H., Tsai, S.B., Yu, J., et al. Exploring key factors in online shopping with a hybrid model. SpringerPlus, (2016), 5:2046, DOI 10.1186/s40064-016-3746-4.

[28] Ge, B., Jiang, D., Gao, Y., and Tsai, S.B. The Influence of Legitimacy on a Proactive Green Orientation and Green Performance: A Study Basedon Transitional Economy Scenarios in China. Sustainability, (2016), 8, 1344, 1-20. 